\title{
Small intestinal mucosal abnormalities in post-perinatal deaths
}

\author{
S VARIEND, R SUNDERLAND \\ From the Department of Pathology, Children's Hospital, Western Bank, Sheffield S10 2TH
}

SUMMARY Examination of small intestinal mucosa from cases of post-perinatal death in Sheffield between September 1980 and September 1981 showed mucosal changes before death in 18 of 78 cases $(20 \%)$. There was no significant difference in prevalence between explained and unexplained deaths, nor was there any positive association with viral isolation from the small intestine. The lesion was much more common in males than females and showed a strong association with bottle feeding - no infant wholly breast fed showed an enteropathy. There was a low incidence of symptoms referrable to the gastrointestinal tract among affected infants, and no appreciable evidence of failure to thrive, as reflected by the postmortem body weight, was present.

Mucosal changes of the small intestine in cases of sudden infant death syndrome have previously been reported and attributed to heatstroke. Although the finding of similar lesions in infants who died explicably does not appear to support this view, overheating is difficult to exclude as most of the explained deaths with a mucosal lesion occurred at home.

Small intestinal mucosal abnormalities in children are fairly well documented and their pathogeneses are complex. Although the basis of considerable morbidity, they are rarely, if ever, directly related to the cause of death. Small bowel changes are infrequently reported in postmortem material, and this may be largely due to difficulty with histological evaluation in the presence of autolytic change. Postmortem mucosal abnormalities of the small intestine have been reported in cases of sudden infant death syndrome, ' where they have been attributed to heatstroke.

Standardised sampling from the small intestine was used in this investigation, and an attempt was made to determine the frequency, extent, and possible aetiology of enteropathic changes in infant deaths. The study was prospective and tissues were rapidly fixed in formalin to minimise autolysis.

\section{Material and methods}

All infants between the ages of one week and one year dying between September 1980 and September 1981 and examined in the department of pathology at the Sheffield Children's Hospital were included in this study. The time interval between death and necropsy varied from $2 \cdot 0$ to $96 \mathrm{~h}$ with a mean of $39 \cdot 9 \mathrm{~h}$.

Accepted for publication 3 November 1983
Postmortem body weights were plotted on Tanner and Whitehouse percentile charts.

The Sheffield paediatric necropsy includes three standard blocks of small intestine: proximal jejunum, mid-jejunum, and terminal ileum. Ileal content was removed aseptically for bacterial culture and was also examined for viruses by electron microscopy using negative staining. Paraffin embedded tissue was sectioned and stained with haematoxylin and eosin.

Enteropathic lesions were classified into three grades based on the degree of villous blunting: $(+)$ mild villous blunting (Fig. 1a); $(++)$ moderate villous blunting (Fig. 1b); $(+++)$ severe or total villous blunting (Fig. 1c). Cases were included only if mucosal changes could be clearly distinguished from autolytic change, and areas showing oblique sectioning or containing mucosal lymphoid tissue were avoided. Clinical details were abstracted from hospital records or coroners' statements.

Eighty seven infants were studied, including 24 in whom death could be explained; this comprised 11 severe congenital malformations, eight infections, four trauma/asphyxia, and one tumour. The birth weight was available in $61(70 \%)$ of the cases, and in seven $(11 \%)$ of these the weight was less than 2500 g. The reason for the proportionately large number of inexpiicable deaths in this series is that the pathology service at the Sheffield Children's Hospital covers all home deaths in the whole of south 


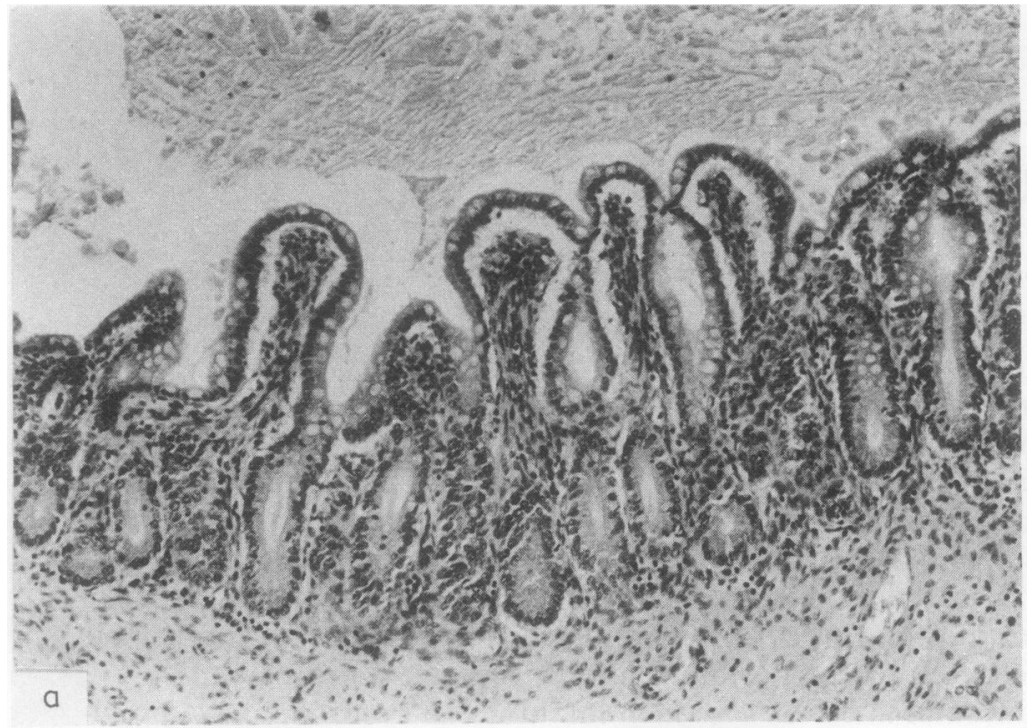

Fig. 1 (a) Grade I mucosa with a mild degree of shortening of villi. Surface epithelium is cuboidal. There is no obvious increase in lamina propria cellularity. (Haematoxylin and eosin. Original magnification $\times 128$ ). (b) Grade Il mucosa moderate blunting and broadening of villi, covered by flattened epithelium. (Haematoxylin and eosin. Original

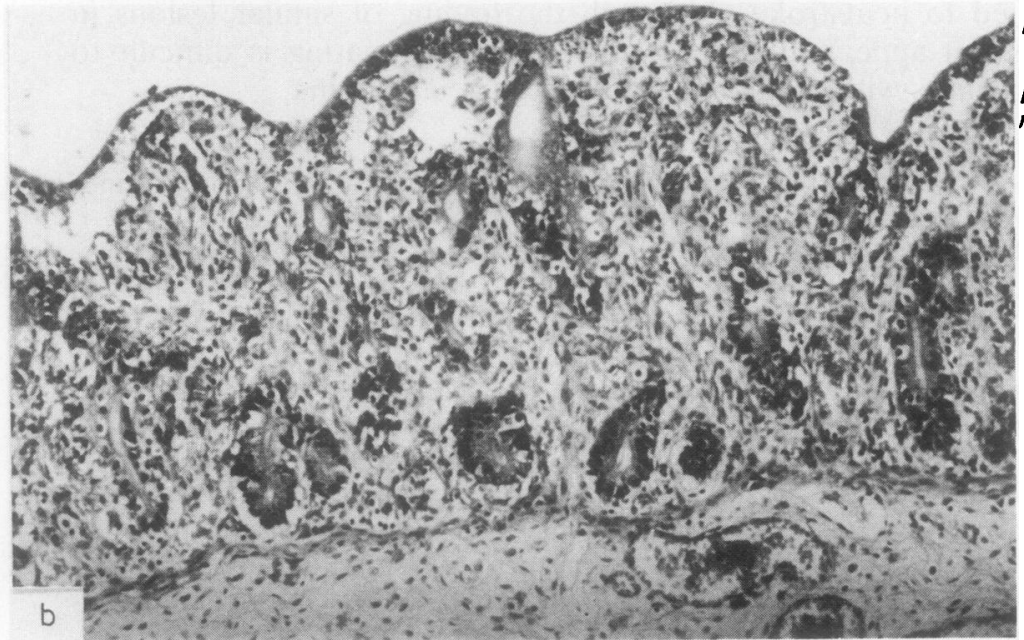
magnification $\times 128$ ). (c) Flat mucosa (grade III) with surface epithelium still intact in places. (Haematoxylin and eosin. Original magnification $\times 128$ ).

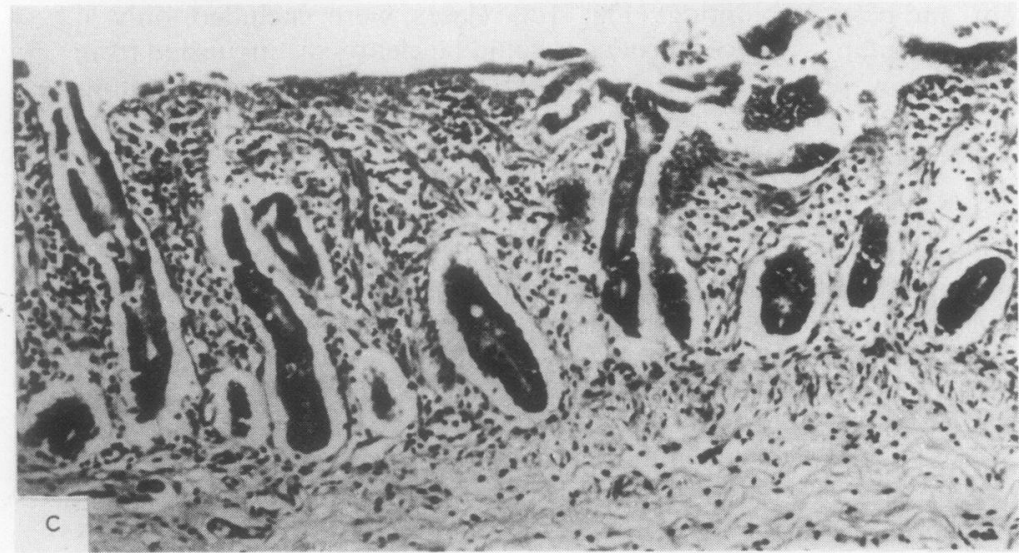


Yorkshire whereas explicable deaths largely occurred at this hospital.

\section{Results}

Mucosal changes were present in 18 infants (four explicable, 14 inexplicable deaths). Details of terminal symptoms and severity of small intestinal mucosal changes are given in the Table. Only four of the 18 had symptoms directly referrable to the gastrointestinal tract. Three infants with enteropathy who died suddenly and inexplicably had no preceding symptoms. In the remainder, symptoms were diverse and non-specific and the degree of enteropathy bore no relation to the type of symptoms. Variable villous blunting and flattening of the surface epithelium characterised the mucosal lesion. These changes were found in 14 of 49 males $(28 \%)$ and four of 38 females (10\%), a significant difference $\left(\chi^{2}=4 \cdot 25\right.$, df $\left.=1, p<0.05\right)$. Lamina propria cellularity was variable and ranged from being moderately increased to slightly depressed. Crypt epithelial degeneration with cellular debris in crypt lumina was an associated feature in 12 of the abnormal mucosae. Although mucosal changes were more or less uniformly distributed along the length of the small intestine, they occasionally tended to dominate distally (Fig. 2).

No bact rial pathogen was isolated from any child, but viruses were found in 12 (adenovirus in five, rotavirus in three, calcivirus in two, small virus

\section{Symptoms related to degree of villous abnormality}

\begin{tabular}{|c|c|c|}
\hline Case no & Symptoms & $\begin{array}{l}\text { Grade of } \\
\text { enteropathy }\end{array}$ \\
\hline 1 & Found pale, limp and grey & + \\
\hline $2 \dagger$ & Vomiting for 3 weeks & + \\
\hline 3 & None & ++ \\
\hline 4 & Cough and "cold" for few days & + \\
\hline 5 & Sleeping poorly/crying a lot for 3 days & $+t+$ \\
\hline 6 & $\begin{array}{l}\text { Found bleeding and frothing at mouth } \\
\text { Moaning for "few" hours }\end{array}$ & $\begin{array}{l}+++ \\
++t\end{array}$ \\
\hline & (gastroenteritis) & \\
\hline $8^{*}$ & $\begin{array}{l}\text { Crying, reluctant to feed (congenital } \\
\text { heart disease) }\end{array}$ & + \\
\hline 9 & Slight cold for 5 days & ++ \\
\hline $10 \dagger$ & $\begin{array}{l}\text { (Previously found ashen) abdominal } \\
\text { pain for } 1 \text { day }\end{array}$ & + \\
\hline 11 & Apnoeic spells since birth (premature) & + \\
\hline 12 & None & + \\
\hline $13 * \dagger$ & Diarrhoea and vomiting for 3 weeks, & \\
\hline 14 & then "cold" for 1 week (pneumonia) & $\begin{array}{l}t+ \\
+t\end{array}$ \\
\hline 14 & $\begin{array}{l}\text { night before } \\
\text { nigitus) Crying a lot }\end{array}$ & \\
\hline $15 \dagger$ & Anorexia and vomiting for $24 \mathrm{~h}$ & +++ \\
\hline 16 & None & ++ \\
\hline $17^{*}$ & $\begin{array}{l}\text { Irritable, pyrexia, poor feeding } 1 \\
\text { day (meningitis) }\end{array}$ & ++ \\
\hline 18 & Found "unwell" & +++ \\
\hline
\end{tabular}

*Explicable deaths with a mucosal lesion.

tSymptoms related to gastrointestinal tract.

\begin{tabular}{|c|c|c|c|}
\hline Case No & Prox & Mid & Distal \\
\hline 1 & + & $N$ & + \\
\hline 2 & + & + & + \\
\hline 3 & $+t$ & $+t$ & $+t$ \\
\hline 4 & $N$ & + & ?N \\
\hline 5 & $t+t$ & $+t+$ & $+t+$ \\
\hline 6 & $N$ & $++t$ & $+t+$ \\
\hline 7 & $t+t$ & $t+t$ & $t+t$ \\
\hline 8 & + & + & + \\
\hline 9 & $+t$ & $+t$ & $+t$ \\
\hline 10 & $N$ & $N$ & + \\
\hline 11 & + & + & + \\
\hline 12 & + & + & + \\
\hline 13 & $+t$ & $+t$ & $+t$ \\
\hline 14 & $N$ & $t+$ & $+t$ \\
\hline 15 & $+t+$ & + & $t+t$ \\
\hline 16 & $+t$ & $+t$ & $+t$ \\
\hline 17 & $+t$ & $+t$ & + \\
\hline 18 & $++t$ & $t+t$ & $+t$ \\
\hline
\end{tabular}

Fig. 2 Distribution of the degree of villous abnormality by grade is shown at the three levels examined. Prox $=$ proximal jejunum; Mid = mid-jejunum; Distal = terminal ileum. Cases with crypt epithelial degeneration are indicated by an asterisk.

in one, and one child had both rotavirus and adenovirus); adenovirus and rotavirus were each found in two unexplained deaths with enteropathy, while rotavirus, calcivirus, and adenovirus were found in six unexplained deaths without enteropathy. Rotavirus, adenovirus, a small virus, and a calcivirus were each found in four explicable deaths with enteropathy. The mean interval from death to necropsy of those with a virus was $35.9 \mathrm{~h}$ (range $7 \mathrm{~h} 15 \mathrm{~min}-96 \mathrm{~h}$ ) and those without a virus was $32 \cdot 1 \mathrm{~h}$ (range $2 \mathrm{~h}-82 \mathrm{~h} 30 \mathrm{~min}$ ). The intervals are not significantly different $(t=0.519, \mathrm{p}>0.5)$.

Feeding histories were available in 66 cases. Ten were wholly breast fed (no enteropathy), eight were breast fed and bottle fed (one with enteropathy), and 48 were wholly bottle fed $(17$ with enteropathy); these differences are statistically significant $\left(\chi^{2}=6 \cdot 235, \mathrm{df}=2, \mathrm{p}<0.05\right)$. Postmortem body weights plotted on percentile charts are shown in Fig. 3. One female with enteropathy had a body weight just below the third percentile for age and, while four males with enteropathy had body weights below the third percentile, two had birth weights less than $2500 \mathrm{~g}$.

The four cases in which death was explicable and which were associated with enteropathy included pneumonia, congenital heart disease, (Ivemark's syndrome with an ostium primum defect), gastroenteritis with severe dehydration, and one case 


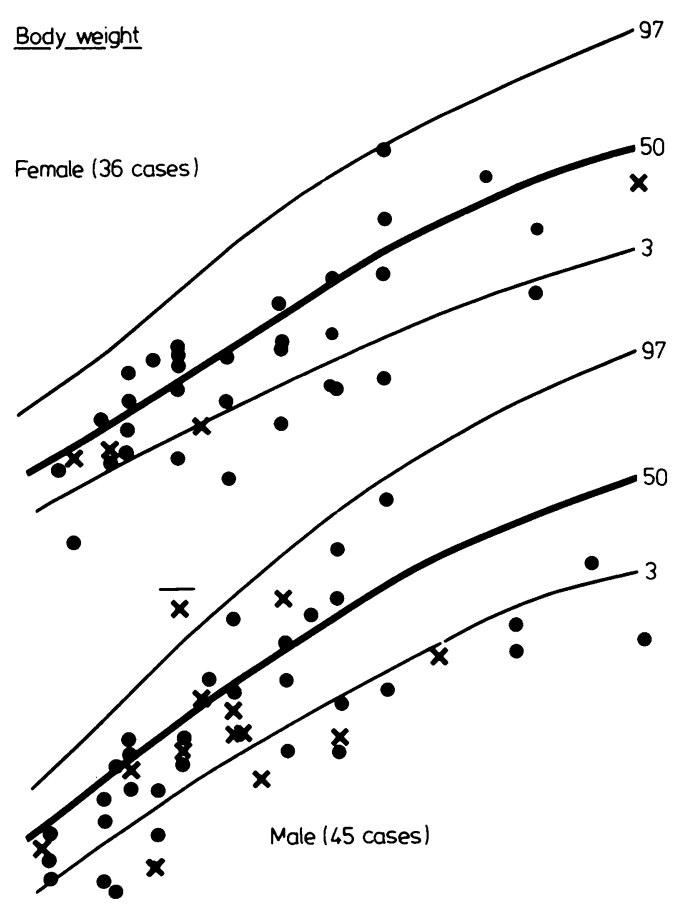

Fig. 3 Postmortem weights on Tanner and Whitehouse percentile charts for females and males: solid circle refers to those without a mucosal lesion; a cross refers to those with a mucosal lesion. Age range 1 week to 1 year.

of Down's syndrome complicated by short segment Hirschsprung's disease and meningitis. The infant with Down's syndrome died in hospital, while the remainder were home deaths. No bacterial pathogen or virus was isolated after death from the infant with gastroenteritis and there was no evidence of necrotising enterocolitis in the child with Hirschsprung's disease.

\section{Discussion}

We are unaware of other studies which have examined necropsy material from infants either prospectively or blind. The increased incidence of the enteropathy among males was significant, and although the male is the weaker gender, ${ }^{2}$ we do not know of any mechanism that lowers the protection of the gut which is mediated by gender. Enteropathy of the small bowel was significantly associated with artificial feeding. Small bowel mucosal changes are found in infants with cows' milk protein sensitivity, ${ }^{3}$ and fatal anaphylactic reactions have been associated with that condition. ${ }^{4}$ Mucosal damage in coeliac disease predominates in the proximal small bowel, ${ }^{5}$ and, although a similar situation is likely to apply in other forms of dietary protein intolerance, the extent of the mucosal lesion in cows' milk protein sensitivity has not, unfortunately, been adequately studied. Lack of any important gastrointestinal symptoms preceding the deaths of these infants, however, and the absence of any appreciable weight loss, as reflected by postmortem body weight, tend to rule against a dietary protein intolerance of appreciable diration. Only one female infant with an enteropathy showed a postmortem body weight below the third percentile and, although there were four such male infants, two had low birth weights and their postmortem body weights may reflect a delay in catch up growth.

This investigation and one by Stanton et al ${ }^{1}$ emphasise the feature of crypt epithelial change with accumulation of cellular debris in the crypt lumina, which is dissimilar to the pattern usually described with cows' milk protein sensitivity as assessed on biopsy material in life. Stanton et al found crypt epithelial degeneration of the small bowel mucosa in eight of the 33 cases of otherwise unexplained deaths, five of which had overwhelming clinical evidence of overheating from excessive clothing or over wrapping. They also referred to a previous report ${ }^{6}$ in which five infants were thought to have succumbed to heatstroke for similar reasons and in whom the mucosal changes were more advanced and included villous flattening and blunting.

As far as we know, viruses identified by electron microscopy in postmortem bowel content have not been previously reported; with this technique, viruses were identified in $15 \%$ of the entire group. There was no significant difference in the time from death to necropsy between the group with and the group without viruses and postmortem autolysis is therefore unlikely to have underrated the actual number of viruses present in life. Of the 12 cases with viruses, only two had a mucosal lesion and in no case with virus were enteric symptoms present. Thus mucosal change appears to be unrelated to the presence of any of the commonly recognised enteric viruses.

A postmortem study in which the small bowel was studied stereologically showed villous malformation mainly distributed in the proximal part ${ }^{7}$ and a biopsy investigation among live infants with clinical gastroenteritis did not describe crypt epithelial changes of the type seen here ${ }^{8}$ presenting further evidence that the mucosal lesion referred to is unlikely to have an infective basis.

The causes of the four explicable deaths with mucosal changes were diverse, and it is, of course, quite possible that the lesion is of heterogeneous aetiology. On the other hand, the significant associa- 
tion with bottle feeding and the preponderance of males does suggest a specific mode of injury. The slightly increased incidence of the mucosal lesion among the unexplained deaths was not significant and is therefore probably not causally related to the sudden infant death syndrome. Since three of the explained deaths with the mucosal lesion occurred at home, however, it would be difficult totally to exclude overheating as having had a role in pathogenesis.

We are grateful to Mr SR Penny for carrying out virological studies and to Mrs BP Wilson for typing the manuscript.

\section{References}

' Stanton AN, Scott DJ, Downham MAPS. Is overheating a factor in some unexpected infant deaths? Lancet 1980;i:1054-7.
${ }^{2}$ Taylor DC. The influence of sexual differentiation in growth development and disease. In: Davies J, Dobbing J, eds. Scientific foundations of paediatrics. London: Heinemann, 1974:19-44.

${ }^{3}$ Fontaine JL, Navaro J. Small intestinal biopsy in cows' milk protein allergy in infancy. Arch Dis Childh 1975;50:357-62.

4 Coombs RRA, McLaughlan P. The enigma of cot deaths: is the modified anaphylaxis hypothesis an explanation for some cases? Lancet 1982; i: 1388-9.

s Creamer B, Leppard P. Post mortem examination of a small intestine in coeliac syndrome. Gut 1965;6:466-71.

${ }^{\circ}$ Bacon C, Scott D, Jones P. Heatstroke in well wrapped infants. Lancet 1979; i:422-5.

7 Walker-Smith JA. Small intestinal morphology in childhood. Arquives de Gastro-enterologia 1972;9:119-30.

${ }^{8}$ Barnes GL, Townley RRW. Duodenal mucosal damage in 31 infants with gastroenteritis. Arch Dis Childh 1973;48:343-9.

Requests for reprints to: Dr S Variend, Department of Pathology, Children's Hospital, Western Bank, Sheffield S10 2TH, England. 